\title{
Southern Annular Mode response to volcanic eruptions: implications for ice core proxies
}

Matthew Toohey (1), Kirstin Krüger (1), Stefanie Zander (1), Ulrike Niemeier (2), and Claudia Timmreck (2)

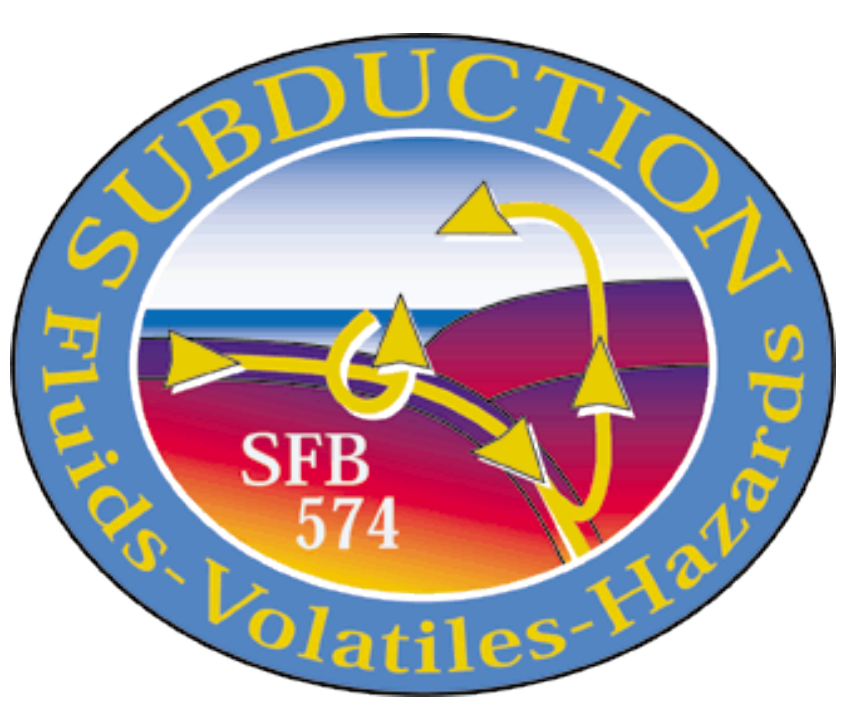

IFM-GEOMAR

(1) IFM-GEOMAR, Kiel, Germany (2) Max-Planck-Institute for Meteorology, Hamburg, Germany

\section{Introduction}

Large tropical volcanic eruptions have been observed' to have a significant influence on the largescale circulation patterns of the Northern Hemisphere (NH), through mechanisms related to the radiative effects of stratospheric volcanic sulfate aerosols. Such atmospheric anomalies can be described as perturbations to the Northern Annular Mode, a mode of

In the Southern Hemisphere, comparable perturbations to the Southern Annular Mode (SAM) after In the Southern Hemisphere, comparable perturbations to the Southern Annular Mode (SAM) after
tropical eruptions have not yet been observed ${ }^{3}$. Here, with a coupled aerosol general circulation mopical eruptions have

1. How strong must a tropical eruption be to produce a significant SAM response?

2. What characterizes a volcanically perturbed SAM state?

3. How could a volcanically perturbed SAM impact Antarctic ice core proxies?

\section{Model simulations}

Volcanic simulations were performed with the MAECHAM5-HAM general circulation model (T42/L39) including detailed aerosol microphysics4. Eruptions are simulated by injecting $\mathrm{SO}_{2}$ into the lower stratosphere $(30 \mathrm{hPa})$. The model then simulates the full lifecycle of the volcanic aerosols, including oxidation of $\mathrm{SO}_{2}$ to $\mathrm{H}_{2} \mathrm{SO}_{4}$ aerosol formation and growth, sedimentation, and the removal processes wet and dry deposition. The model is run in a free-running climate mode, with modern day external forcings, including climatological SSTs. Eruptions with a wide range of stratospheric $\mathrm{SO}_{2}$ injection magnitudes are simulated, with eruptions in January and July. All eruptions are situated at $14^{\circ} \mathrm{N}$,
$91^{\circ} \mathrm{W}$, the site of the Los Chocoyos ( $\left.\sim 84 \mathrm{ka} \mathrm{BP}\right)$ eruption, the largest eruption $\left(\sim 700 \mathrm{Tg} \mathrm{SO}_{2}\right)$ in the Central American Volcanic Arc (CAVA) timeseries of the last 200ka (Metzner et al., submitted manuscript). Simulations of the Los Chocoyos eruption are referred to as the $E 700$ experiment.

\section{Atmospheric} dynamics

A direct result of the injection of volcanic aerosols is heating of the lower stratosphere throug the absorption of long wave radiation emitted by the Earth's surface.

- In our E700 simulations, the creation of volcanic aerosols leads to strong temperature anomalies in the tropical lower stratosphere, of magnitudes $>20 \mathrm{~K}$ (Fig. This heating leads to a stronger equator to pole temperature gradient, whic in turn leads, through the thermal wind balance, to stronger zonal winds.

The zonal wind anomalies are strongest in the stratosphere, but significant anomalies (>10 $\mathrm{m} / \mathrm{s}$ ) extend down to the surface, especially in the $\mathrm{SH}$.

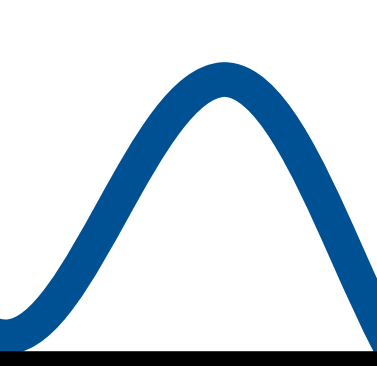

\section{Southern Annular Mode response \\ The SAM Index can be defined as the difference in the normalized} monthly zonal mean pressure anomalies between $40^{\circ}$ and $65^{\circ} \mathrm{S}^{6}$. In our volcanic simulations:

Following very strong eruptions (e.g., E700, Fig. 2) the SAM index is clearly skewed toward positive values, with significant anomalies occurring in the first year, and a tendency towards positive values lasting up to 4 years.

The strength of the first-year mean SAM response is directly related to the magnitude of the stratospheric $\mathrm{SO}_{2}$ injection (Fig. 3)

Significant SAM response, defined as a SAM anomaly that is greater than twice the standard deviation of the SAM of a 20 year control run, is produced in the stratosphere for a eruption with $>15 \mathrm{Tg} \mathrm{SO}_{2}$ injection. At the surface, where the natural variability is larger, one requires an eruption of $>90 \mathrm{Tg} \mathrm{SO}_{2}$ to produce a significant response.

Meteorological anomalies (e.g., for E700, Fig. 4) show a clear picture of extreme impact of volcanically induced SAM.

Sea level pressure anomalies show a classic positive SAM structure, with relatively zonally symmetric anomalies.

Westerly wind anomalies over the Southern ocean are strongest at $\sim 60^{\circ} \mathrm{S}$

Significant easterly wind anomalies present at $\sim 40^{\circ} \mathrm{S}$

Precipitation anomalies follow a banded structure, with a dry Antarctic continent, wet Antarctic peninsula and Southern Ocean, dry band arot
Australia.

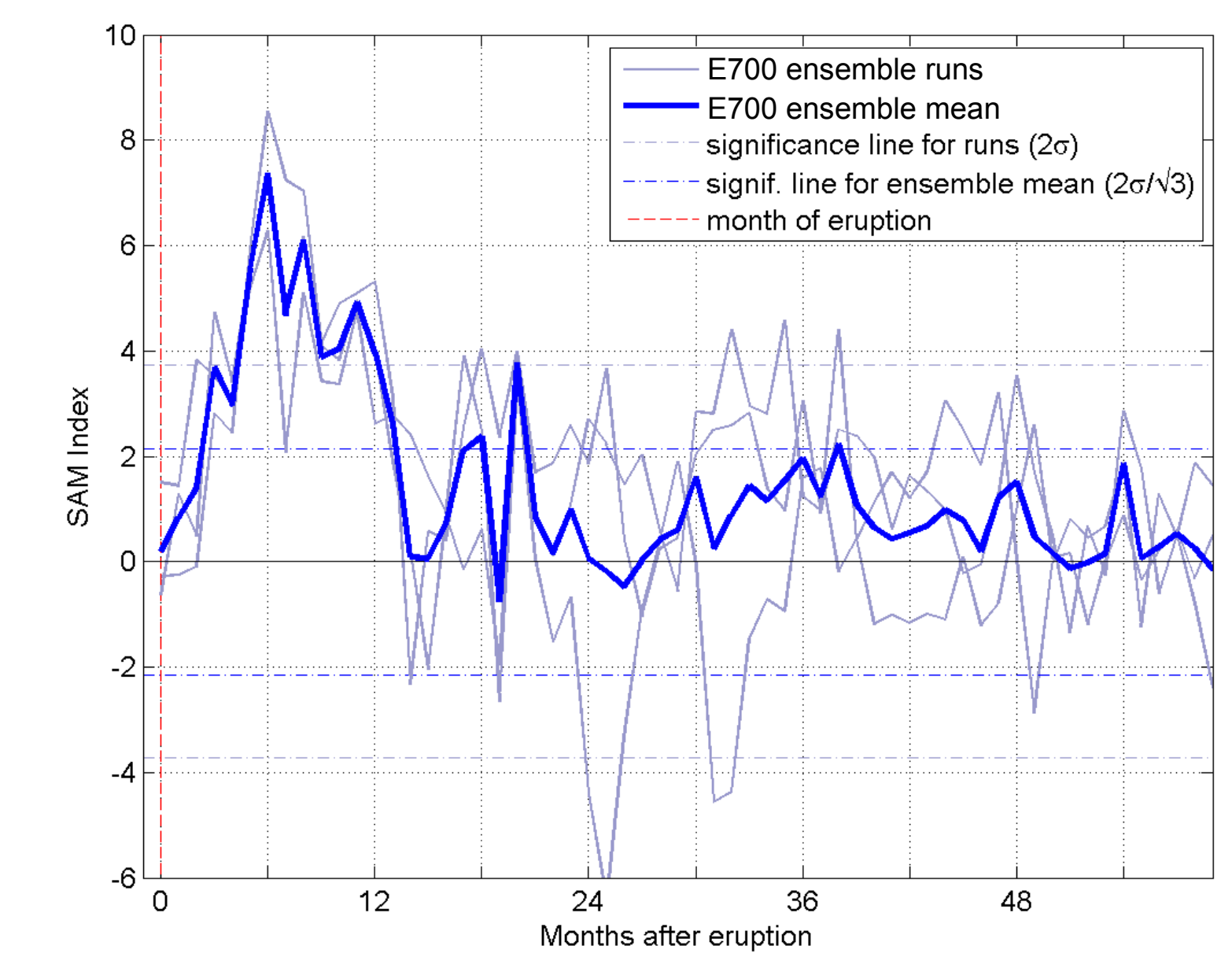

Figure 2: Post-eruption SAM index evolution, for 3 ensemble mean.

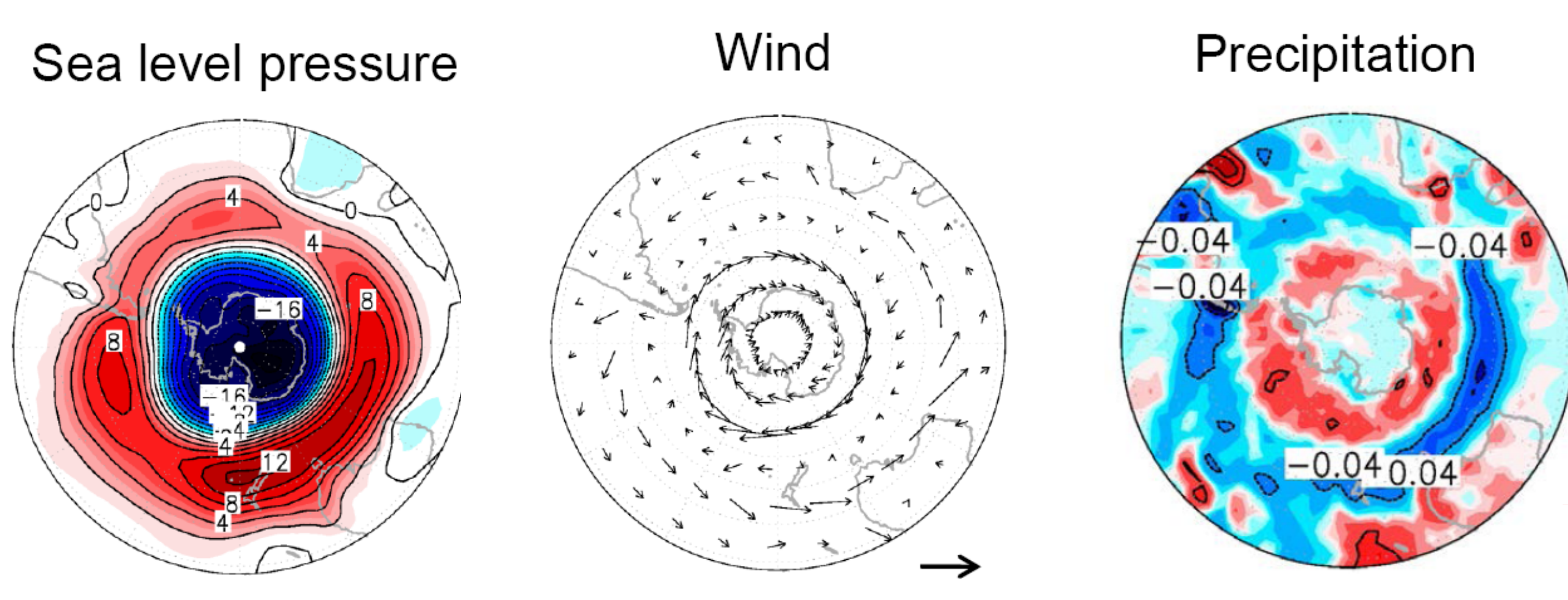

$\overrightarrow{8(\mathrm{~m} / \mathrm{s})}$

Figure 4: First post-eruption winter meteorological anomalies for

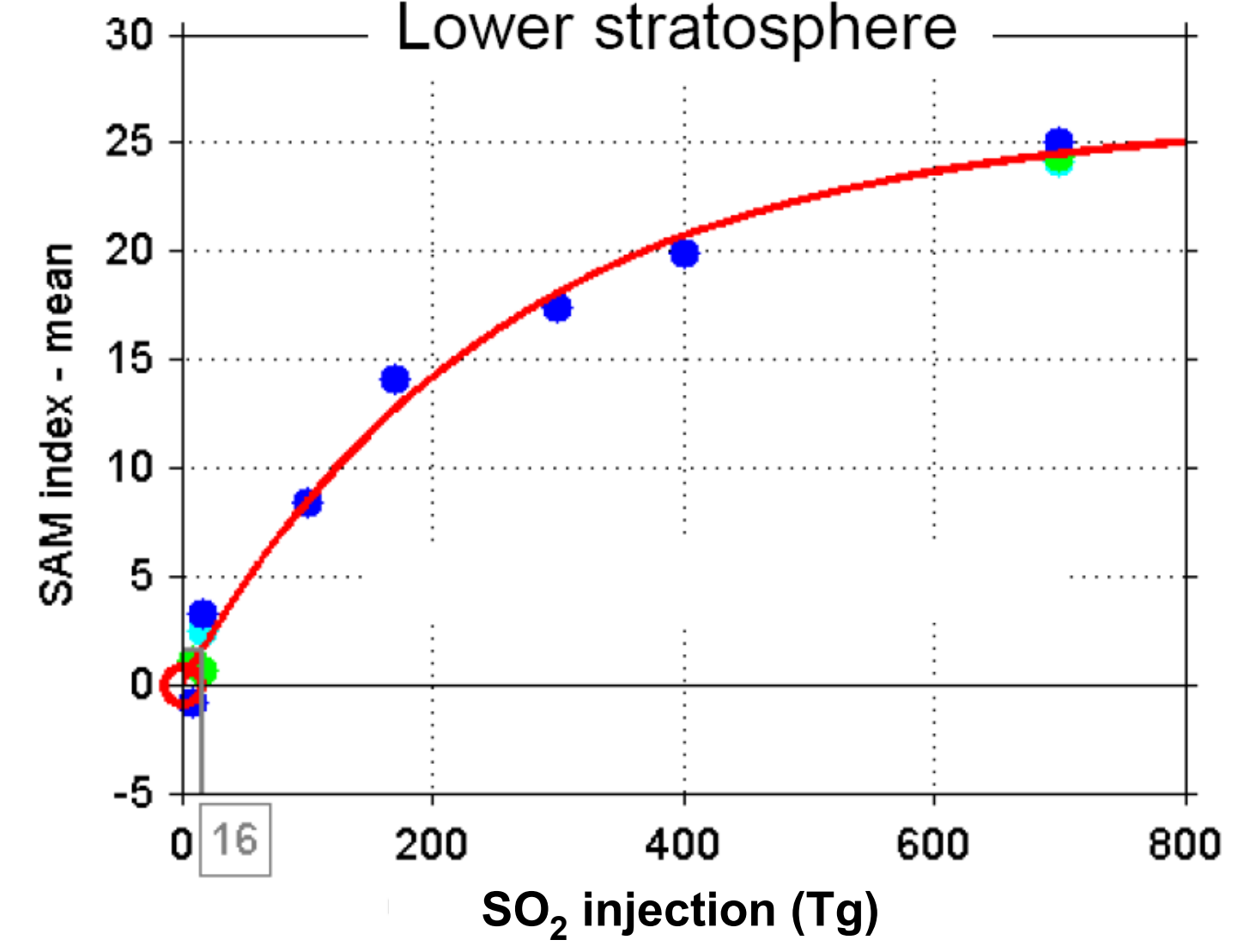

Figure 3: Post-eruption year 1 mean SAM index for January eruption simulations of different $\mathrm{SO}_{2}$ injection magnitude, in terms of $50 \mathrm{hPa}$ geopotential height (lower stratosphere, left) and sea
level pressure (right).
Sulfate loading $\left(\mathrm{kg} / \mathrm{km}^{3}\right)$
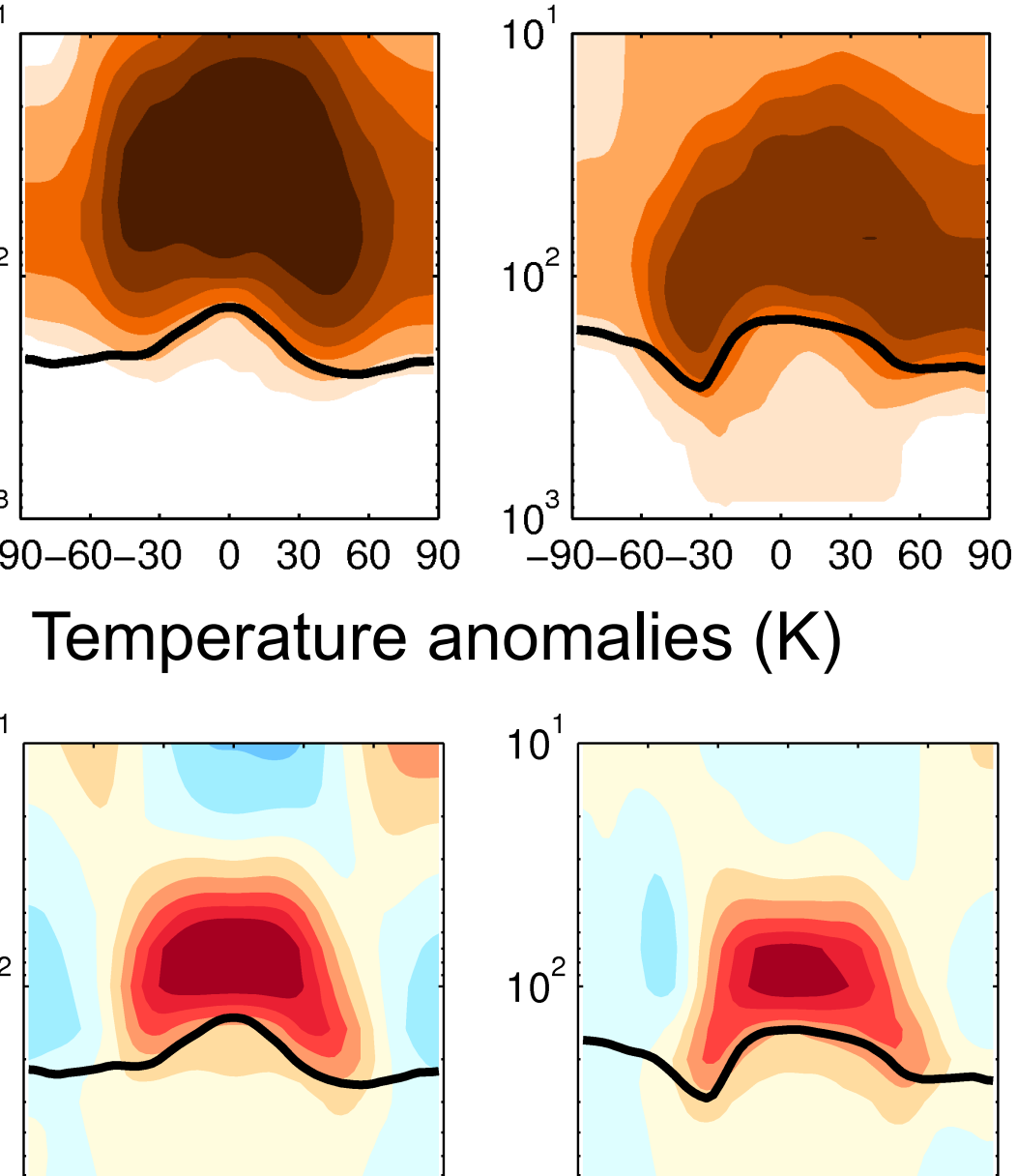

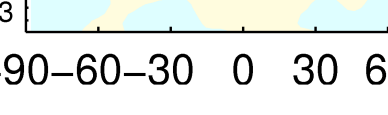
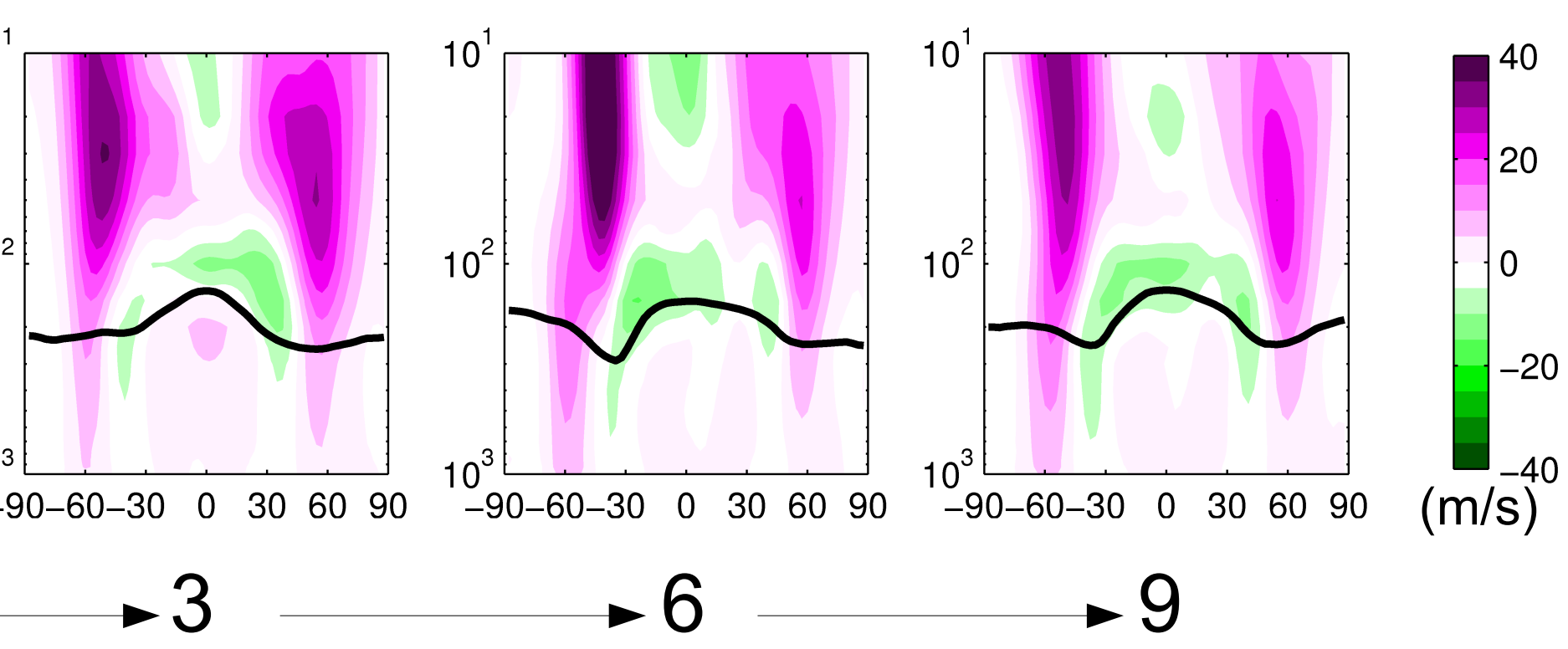

Figure 1: Post-eruption monthly mean, zonal mean sulfate loading (bottom) for the E700 January eruption experiment.

\section{Antarctic sulfate deposition

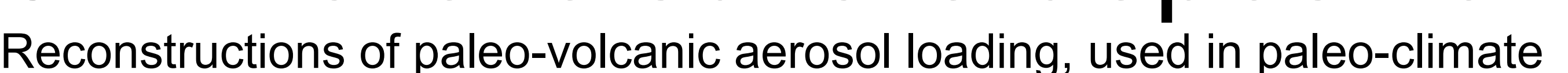
modeling, are based on ice core sulfate records. Ice core sulfate levels are used to infer stratospheric aerosol loading, through a scaling factor, itself based on deposition of material from nuclear bomb tests and modern eruptions ${ }^{7}$. This
method assumes linearity, but could changes in atmospheric dynamics brought method assumes linearity, but could changes in atmospheric dynam
about by the volcanic aerosols affect the deposition to ice cores?

We define an "ice core deposition efficiency" as the average sulfate deposition to the Antarctic (and Greenland) land masses divided by the hemispheric sulfate mass burden.

- For eruptions larger than $45 \mathrm{Tg} \mathrm{SO}_{2}$ injection, Antarctic deposition efficiency

decreases with increasing eruption magnitude (Fig. 5, left).

For such eruption magnitudes, Antarctic deposition efficiency is negatively correlated with post-eruption SAM anomaly (Fig. 5, right). Thus, the strong westerly winds at the Antarctic coastline, and the related decrease in Antarctic continental precipitation lead to a relative decrease in sulfate deposition to the Antarctic ice sheets for strong eruptions.

Compared to Greenland ice sheets, Antarctic ice sheets are a much less efficient sink of volcanic sulfate for large eruptions (Fig. 6).
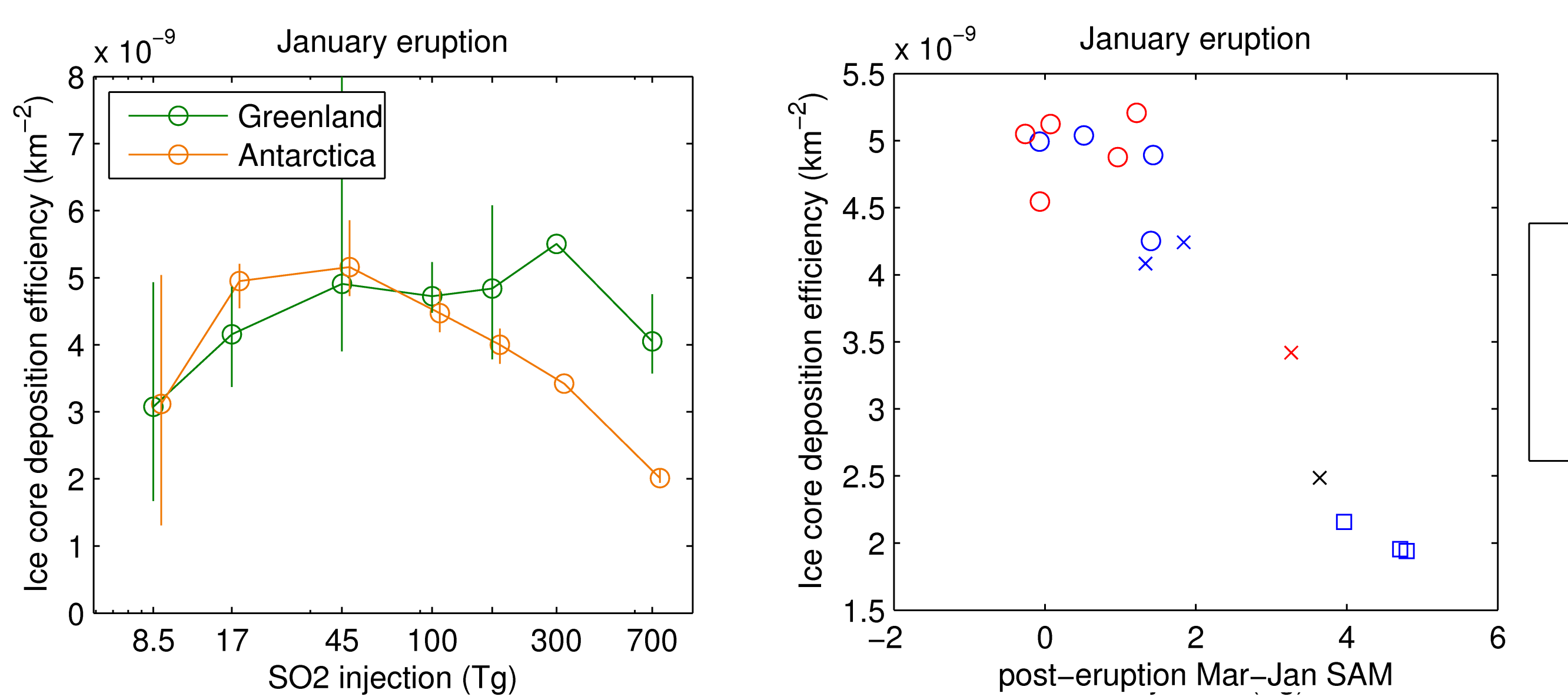

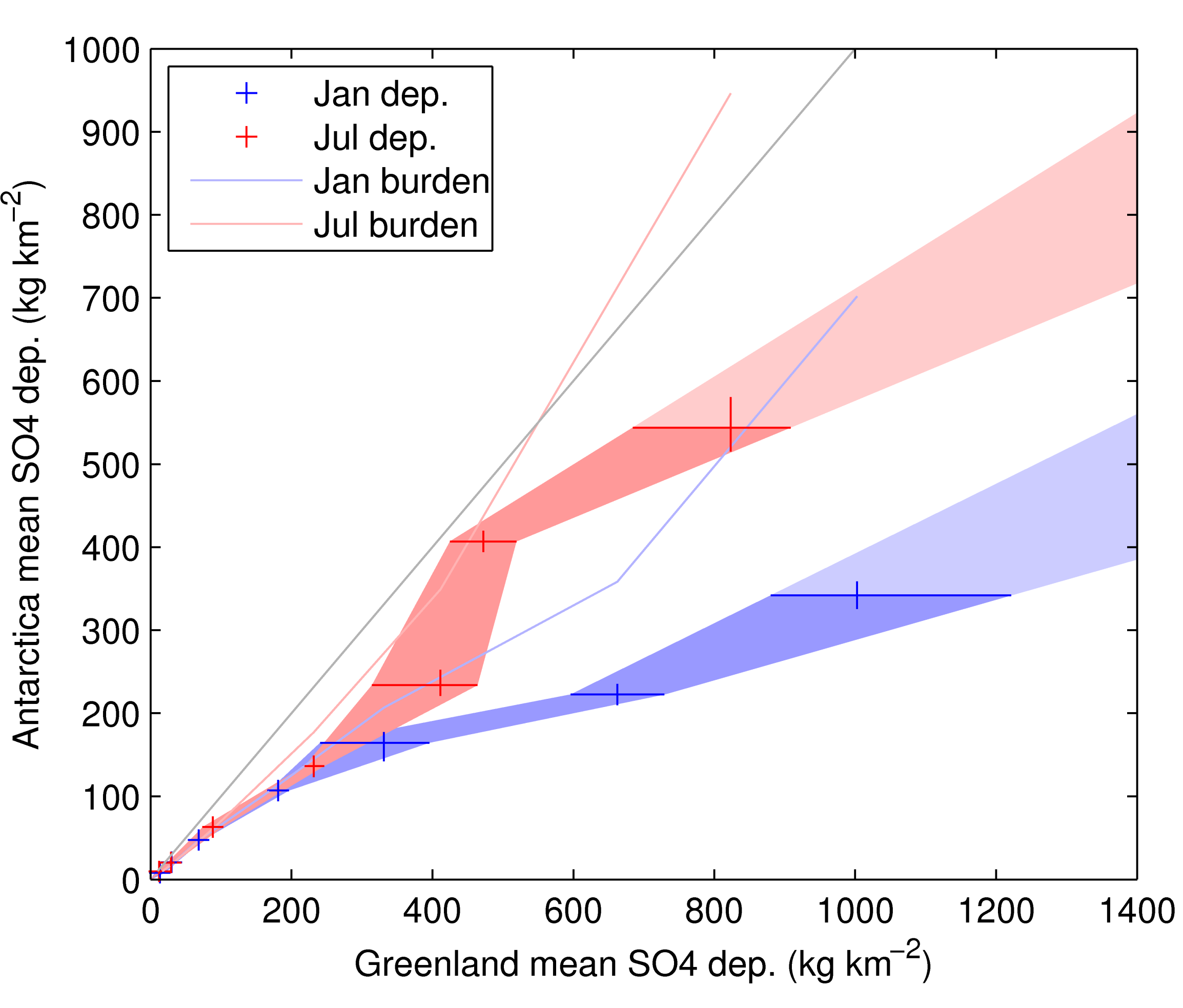

Figure 6 (above): Sulfate deposition to the Antarctic vs. Greenland ice sheets, for January (blue crosses and shading) and July (red
crosses and shading) eruptions. Relative ratio of hemispheric atmospheric sulfate burden shown by red and blue lines.

Figure 5 (to left): Ice core deposition efficiency, as a function of $\mathrm{SO}_{2}$ injection magnitude (left) and post-eruption SAM index (right).

\section{Conclusions}

Tropical volcanic eruptions can have strong impacts on which can be well

- Eruptions with $\mathrm{SO}_{2}$ injection magnitudes of around the size of the $1991 \mathrm{Mt}$. Pinatubo eruption have significant impacts on stratospheric dynamics, but it requires a stronger eruption (4-5 times) to have a significant impact on the surface SAM. - Eruptions of sufficient stratospheric sulfur injection magnitude lead to classic positive SAM-like response with low pressure over Antarctica, strong westerly wind anomalies over the Southern Ocean, and banded precipitation anomalies.

The deposition of sulfate to the Antarctic polar ice sheet is strongly dependent on eruption magnitude. Sulfate deposition to Antarctica is strongly diminished for very large amounts of stratospheric $\mathrm{SO}_{2}$ injection and is a symptom of SAM perturbations.

Due to the SAM influence on ice sheet deposition sulfate deposition to Antarctica for extremely large eruptions (e.g., Toba, $\sim 73$ ka BP) could be less than a third that to Greenland

Proper reconstruction of volcanic timeseries from icecore sulfate records should account for the effects of anomalous atmospheric dynamics brought about by aerosol heating after explosive tropical eruptions.

\section{References}

Stenchikov G. Arctic Oscillation response to the 1991 Mount Pinatubo
eruption: Effects of volcanic aerosols and ozone depletion. Journal of Geophysical Research. 2002 Thompson DWJ, Wallace JM. Annular Modes in the Extratropical Circulation. 2. The Robock A, Adams T, Moore M, Oman L, Stenchikov G. Southern Hen
atmospheric circulation effects of the 1991 Mount Pinatubo eruption. Geophysical Research Letters. 2007. 4. Niemeier U, Timmreck C, Graf H-F, et al. Initial fate of fine ash and sulfur from large volcanic eruplions. Atmospheric Chemistry and Physics. 2009. Toohey M, Krüger K, Niemeier $\mathrm{U}$, Timmreck C. The influence of eruption
season on the global aerosol evolution and radiative impact of tropical volcanic eruptions. Submitted to Atmospheric Chemistry and Physics. 2011. Gong D, Wang S. Definition
Research Letters. 1999 . Gao C, Robock A, Ammann C. Volcanic forcing of climate over the past 1500
years: An improved ice core-based index for climate models. Journal of 